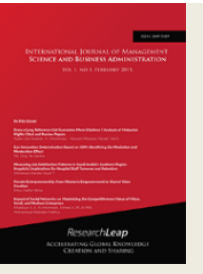

\title{
Moderating Effect of Environmental Uncertainties on the Relationship between Risk Hedging Supply Chain Strategy and Performance of Manufacturing Firms in Kenya
}

\author{
1 * Karani Anthony Muriithi, ${ }^{2}$ Odari Sammy, ${ }^{3}$ Noor Shalle \\ ${ }^{1,2,3}$ Department of Procurement of Procurement and Logistics, School of Business and Entrepreneurship, \\ Jomo Kenyatta University of Agriculture and Technology \\ *Corresponding author's e-mail: karaniel56@gmail.com
}

Abstract: The manufacturing sector in Kenya is faced by the challenges of performance and unstructured supply chain strategy. Further, the manufacturing sector growth in 2014 was 3.4\% compared to a 5.6\% growth in 2013 (Waiguru, 2015). This slow growth in manufacturing sector performance can be attributed to several environmental uncertainties such as the general election, high production costs, supply disruptions, political stability, unavailability of raw materials or demand fluctuations, technological changes, employees' strikes, financial risk, terrorism and competition from imported goods (KNBS, 2018). The purpose of the study was to determine the moderating effect of environmental uncertainties on the relationship between risk hedging supply chain strategy and performance of manufacturing firms in Kenya. The study utilized descriptive research design. The target population was 829 managers from manufacturing firms around the country. A sample of 270 managers was selected using stratified random sampling. Results indicated that risk hedging supply chain strategy explained $63.8 \%$ of the total variations in performance of manufacturing firms. In addition, risk hedging supply chain strategy had a positive and significant effect on firm performance $(\beta=0.675, \mathrm{P}<.000)$. With introduction of moderating variable (environmental uncertainties); risk hedging supply chain strategy explained $34 \%$ of the total variations in performance of manufacturing firms. This denoted those environmental uncertainties had a negative moderating effect on the relationship between risk hedging supply chain strategy and performance of manufacturing firms in Kenya. The study concluded that risk hedging supply chain strategy had a positive and statistically significant effect on performance of manufacturing firms in Kenya. The study further concluded that environmental uncertainties lower the effect of risk hedging supply chain strategy on firm performance. The study recommends that manufacturing firms should strengthen aspects related to risk hedging supply chain strategy. The firms should particularly strengthen safety stock, suppliers' management and quality. The improvement of these aspects is expected to enhance performance of the manufacturing firms. This study further recommends that manufacturing firms should factor in environmental uncertainties related to demand, supply and technology when implementing supply chain strategies.

Keywords: Environmental Uncertainties, Risk Hedging Supply Chain Strategy, Performance, Manufacturing Firms.

\section{Introduction}

The Kenya National Statistics Bureau (KNBS) Economic Survey of 2018 demonstrated that the real value added value of the manufacturing sector in the country grew marginally by 0.2 percent in 2017 compared to a 2.7 percent increase in 2016. The production volume of the sector declined by 1.1 percent, primarily due to a decrease in food products, drinks and tobacco, leather and associated goods, sub-sectors of rubber and plastics and non-metallic minerals. The industry was negatively impacted by uncertainties concerning the extended electioneering period, an increase in inflation, high cost of manufacturing and competition from imported products. The prohibition on the manufacture and use of plastic carrier bags also had adverse effects on the sector's output quantity (KNBS, 2018).

There has upward trajectory in awareness among practitioners and academicians in the area of supply chain risk management (Colicchia \& Strozzi, 2012). Despite this, the research is far from being complete particularly in understanding, reducing, managing, and mitigating uncertainty and risk in supply chains (SCs) (Tang, 2016). Lee (2014) suggested Tripartite principle for formulating robust supply chain strategies to caution against disruptions in the chain. 
This is fostering common interests across supply chain partners, adapting to volatile demands and supply and agility to be able to respond to the effects of short-term fluctuations in the equilibrium of demand and supply.

Key source of environmental risks are customers (request), providers (supply), innovation and contenders (Fynes, de Búrca \& Marshall, 2014; Sun, 2010), while other prior research have distinguished a few sources of vulnerability, for example, request, producing procedure, supply and control vulnerability. Minimal scholarly research has been done to decide both internal and external factors that influence production network execution which principally comprises of environmental risks (Merschmann \& Thonemann, 2011).

For any firm to achieve performance, its supply chain strategies should lead to superior performance within the supply chain at firm level (Spekman, Kamauff \& Salmond, 2014). The manufacturing sector in Kenya is faced by the challenges of performance and unstructured supply chain strategy (PWC, 2010). Volatility of end customers demand, short product lifecycles, price and quality fluctuations, continuous market dynamics have led to challenges in the ability of firms being responsive in the supply chains (Collichia \& Strozzi, 2012).

However, according to KAM (2018) one of the key drivers of manufacturing sector performance is effective supply chain management and adoption of the right supply chain strategies. Formulation and development of unique supply chain strategies are critical for survival and performance of organizations (Stewart, 2015). Zara Fashion, a market leader in apparel industry has maintained good performance due to its unique supply chain strategies (Supply chain Opz, 2018). According to Awino and Gituro (2011) different supply chain strategies are needed to manage the flow of goods from the point of origin to the consumer in order to manage uncertainty in the business environment. However, most firms have not been able to formulate the right strategies required to achieve efficient supply chains and firm performance in supply chain management. This study aimed to determine the moderating effect of environmental uncertainties on the relationship between risk hedging supply chain strategy and performance of manufacturing firms in Kenya.

\section{Literature Review}

The study was based on Dynamic Capabilities Theory. Dynamic capabilities are recognized as strategic alternatives that organizations use when the chance arises to allocate their regulated funds (Schilke, 2014). The word dynamic implies the capacity to renew skills in order to attain consistency with the evolving company setting. This idea is crucial as inability to comprehend and adapt to environmental modifications will result in bad results. Strategic awareness is recognized as a specific capacity that involves shaping the company's strategic position. Companies regard their strategic plan as essential for their strategic consciousness, which emphasizes reasonable behavior and decisions (Wiesner \& Millet, 2012).

Improving dynamic capacity means choosing an approach that results in lower expenses (Schilke, 2014). Companies with honorable intention to alter can attain higher output than their rival as they deploy substantial resources to create their capacities by taking on the necessary approach. A difficult issue rises the equilibrium between managed assets and dynamic capabilities, as there is a danger of a resource development failure on company capacities and strategies. The theory of dynamic capacities examines how companies react to dynamic environmental hazards and uncertainties by integrating the correct sustainability capacities and strategies in their performance (Huesch, 2013). As a result, manufacturing units, dynamic capabilities and strategies are all aimed at achieving the performance of the organization in changing and unpredictable environments. This is clarified by the ongoing growth of particular skills and strategies to deal with changing setting based on the procedures, routes and positions of an organization. Process will involve how an organization conducts its operations while routes will be the main resources of intellectual property, technology, complementary assets, supplier relationships and client base. At the same moment, routes will be the strategic options that an organization will have to consider its procedures and positions. Process will involve how an organization conducts its operations while routes will be the main resources of intellectual property, technology, complementary assets, supplier relationships and client base. At the same moment, routes will be the strategic options accessible to an organization, taking into account its procedures, positions and climate aimed at gaining competitive benefit (Teece, 2014).

Liu, Chen, Li and Zhai (2014) did a study on risk hedging in a supply chain. The study focused on two risk hedging strategies which included option contract and advance purchase discount contract, in a two echelon supply chain. The study further focused on optimal decisions under each contract for both the supplier and the retailer respectively. The study was cross sectional in nature and derived the conditions under which either contract should be adopted from the supplier's perspective. The study further demonstrated that supply chain coordination could be reached under the option contract. The study focused on risk hedging in supply chain and left out the aspect of how the risk hedging supply chain affects performance.

According to Krey and Riahi (2013) from their study on risk hedging strategies under energy system and climate policy uncertainties. The study objectives were to identify characteristics of least-cost risk hedging strategies that are 
implemented to decrease future risks and future uncertainties. The research found that there are strong interactions and synergies between different types of uncertainties. Cost-effective risk hedging strategies therefore needs to take a holistic view and comprehensively account for all uncertainties jointly. With regards to costs, relatively modest risk hedging investments can decrease the vulnerability of the energy system against the related uncertainties.

\section{Research Methodology}

The study used a descriptive research survey and further used both qualitative and quantitative approaches. The target population was 829 respondents from manufacturing firms around the country. The study used stratified random sampling in data collection. A sample of 270 respondents was randomly selected to participate in this study. Primary data was used for the study. The data was collected using open ended and close ended questionnaires. Descriptive statistics and regression analysis were used to analyze the data. Data was presented using tables.

\section{Results and Discussion}

\subsection{Descriptive Statistics on Risk Hedging Chain Strategy}

The respondents were asked to indicate their agreement or disagreement with the statements on risk-hedging supply chain strategy using a five level likert scale (1- strongly agree, 2-agree, 3-neutral, 4- disagree, and 5- strongly disagree). The results are shown in Table 1.

The findings reveal that majority of the respondents agreed with the statement that they usually keep safety stock (64.3\%), they don't suffer stock outs $(68.3 \%)$, they contract many suppliers for supply (63.9\%), they establish long term relationships with suppliers (61.9\%), and they develop the suppliers' capacity $(67.8 \%)$. Further, the respondents noted that they established quality requirements in their processes $(55 \%)$, they ensure compliance to quality requirements $(59.9 \%)$ and they share quality standards with suppliers (55\%).

The aggregate mean of 2.3 indicated that majority of the respondents agreed with the statements about risk hedging supply chain strategy. This means that most of the manufacturing firms have adopted the use of risk hedging supply chain strategy. In particular, the firms have adopted safety stock, suppliers' management and quality. Additionally, the overall standard deviation of 1.2 implied that the data was distributed around the mean. This denoted that majority of the respondents' shared similar opinion in regard to most of the statements on risk-hedging supply chain strategy.

Table 1: Descriptive Statistics on Risk-Hedging Supply Chain Strategy

\begin{tabular}{|c|c|c|c|c|c|c|c|}
\hline Statements & SA & $\mathbf{A}$ & $\mathbf{N}$ & D & SD & M & $\begin{array}{l}\text { STD. } \\
\text { DEV }\end{array}$ \\
\hline We usually keep safety stock & $27.7 \%$ & $36.6 \%$ & $13.4 \%$ & $20.3 \%$ & $2.0 \%$ & 2.3 & 1.1 \\
\hline $\begin{array}{l}\text { We don't suffer stock outs } \\
\text { We contract many suppliers }\end{array}$ & $29.2 \%$ & $39.1 \%$ & $13.4 \%$ & $16.3 \%$ & $2.0 \%$ & 2.2 & 1.1 \\
\hline $\begin{array}{l}\text { for supply } \\
\text { We establish long term }\end{array}$ & $30.2 \%$ & $33.7 \%$ & $18.3 \%$ & $14.4 \%$ & $3.5 \%$ & 2.3 & 1.1 \\
\hline $\begin{array}{l}\text { relationships with suppliers } \\
\text { We develop our suppliers' }\end{array}$ & $29.2 \%$ & $32.7 \%$ & $14.9 \%$ & $19.3 \%$ & $4.0 \%$ & 2.4 & 1.2 \\
\hline $\begin{array}{l}\text { capacity } \\
\text { We have established quality }\end{array}$ & $36.6 \%$ & $31.2 \%$ & $16.8 \%$ & $14.4 \%$ & $1.0 \%$ & 2.1 & 1.1 \\
\hline & $31.2 \%$ & $23.8 \%$ & $18.8 \%$ & $23.8 \%$ & $2.5 \%$ & 2.4 & 1.2 \\
\hline $\begin{array}{l}\text { quality requirements } \\
\text { We share our quality }\end{array}$ & $28.7 \%$ & $31.2 \%$ & $13.4 \%$ & $22.8 \%$ & $4.0 \%$ & 2.4 & 1.2 \\
\hline standards with our suppliers & $31.7 \%$ & $23.3 \%$ & $16.3 \%$ & $25.2 \%$ & $3.5 \%$ & 2.5 & 1.3 \\
\hline Aggregate mean & & & & & & 2.3 & 1.2 \\
\hline
\end{tabular}

The respondents were asked to suggest other factors that affect risk hedging supply chain strategy in their firms. Based on the responses, several factors were identified as critical in determining the effectiveness of risk hedging supply chain strategy. These included: avoidance of risks, reduction of risks, sharing of risks and retention of risks. Majority of the respondents observed that the above mentioned factors were key in improving risk hedging supply chain strategy in the manufacturing firms.

\subsection{Regression Analysis}


The regressions results are presented in Table 2. The model summary results indicate that risk hedging supply chain strategy explains $63.8 \%(\mathrm{R} 2=.638)$ of the total variations in the performance of manufacturing firms. The ANOVA results reveal an F statistic of 352.857 and reported $\mathrm{P}$ value of 0.000 . The $\mathrm{P}$ value being less than the alpha value $(\mathrm{P}<$ .05 ), the proposed model is therefore statistically significant (good fit) in predicting the dependent variable.

Further, the regression of coefficient findings indicate that risk hedging supply chain strategy had a positive and significant effect on firm performance $(\beta=0.675 \mathrm{P}<.000)$. This implied that a change in risk hedging supply chain strategy by one unit would result to change in performance of manufacturing firms by 0.675 units. The study supported Birhanu, Lanka and Rao (2014) findings that adoption of risk hedging supply chain strategy enhances competitiveness of businesses and the market position against their rivals. Kouvelis, Wu and Xiao (2019) found that the correlation of cash flow risks of supply chain partners significantly affects the hedging decisions of firms via impacts on production efficiencies. In addition, Kiio and Jagongo (2017) established a positive relationship between hedging practices and performance of listed firms.

Model;

Firm Performance $=0.816+0.675$ Risk Hedging Supply Chain Strategy

Table 2: Regression Model: Risk Hedging Supply Chain Strategy and Firm Performance

\begin{tabular}{llccccc}
\hline Model & & \multicolumn{2}{c}{ Unstandardized Coefficients } & \multicolumn{3}{c}{ Standardized Coefficients } \\
& & B & Std. Error & Beta & t & Sig. \\
\hline 1 & (Constant) & .816 & .084 & & 9.671 & .000 \\
& Risk Hedging & .675 & .036 & .799 & 18.784 & .000 \\
& R Squared & .638 & & & & \\
& Adjusted R Squared & .636 & & & \\
& F statistic & 352.86 & & & & \\
& P value & .000 & & & & \\
\end{tabular}

\section{a Dependent Variable: Y}

Following the introduction of moderating variable (environmental uncertainties); the results in Table 3 indicate that risk hedging supply chain strategy when interacted with environmental uncertainties explains $34 \%$ of the total variations in performance of manufacturing firms. A comparison between the $\mathrm{R}$ square without moderation and $\mathrm{R}$ square with moderation reveal that the $\mathrm{R}$ square declined from $64 \%$ to $34 \%$, implying that environmental uncertainties had a negative moderating effect on the relationship between risk hedging supply chain strategy and performance of manufacturing firms in Kenya. This means that environmental uncertainties significantly lower the effect of risk hedging supply chain strategy on firm performance.

Model;

Firm Performance $=1.629+0.145$ Risk Hedging Supply Chain Strategy*Environmental Uncertainties

Table 3: Regression Model with Moderation

\begin{tabular}{lccccc}
\hline & \multicolumn{2}{c}{ Unstandardized Coefficients } & \multicolumn{3}{c}{ Standardized Coefficients } \\
& $\mathrm{B}$ & Std. Error & Beta & t & Sig. \\
\hline (Constant) & 1.629 & .077 & & 21.080 & .000 \\
X2.M & .145 & .014 & .579 & 10.034 & .000 \\
R Square & 0.335 & & & & \\
Adj. R Square & 0.331 & & & & \\
F statistic & 100.671 & & & & \\
P value & 0.000 & & & & \\
\hline
\end{tabular}

\section{Conclusion and Recommendations}


The study concluded that risk hedging supply chain strategy had a positive and statistically significant effect on performance of manufacturing firms in Kenya. The study established safety stock, suppliers' management and quality as essential risk hedging supply chain strategies likely to boost firm performance. The study further concluded that environmental uncertainties moderate the relationship between risk hedging supply chain strategy and performance of manufacturing firms in Kenya. In particular, environmental uncertainties lower the effect of risk hedging supply chain strategy on firm performance.

The study recommended that manufacturing firms should strengthen aspects related to risk hedging supply chain strategy. The firms should particularly strengthen safety stock, suppliers' management and quality. The improvement of these aspects is expected to enhance performance of the manufacturing firms. The study further recommended that manufacturing firms should consider environmental uncertainties such as technology.

\section{References}

- $\quad$ Awino, Z., \& Gituro, W. (2011). An Empirical Investigation of Supply Chain Management Best Practices in Large Private Manufacturing Firms in Kenya.

- $\quad$ Birhanu, D., Lanka, R., \& Rao, K. (2014). A survey of classifications in supply chain strategies. Elsevier Journal of Procedia Engineering, Vol 97, Issue 1, pp. 2289 - 2297. Crossref

- $\quad$ Colicchia, C., \& Strozzi, F. (2012). Supply chain risk management: a new methodology for a systematic literature review. Supply Chain Management: An International Journal, Vol.17, Issue 1, pp.403- 418. Crossref

- $\quad$ Fynes, B., de Búrca, S., \& Marshall, D. (2014). Environmental uncertainty, supply chain relationship quality and performance. Journal of Purchasing and Supply Management,

Vol.10 Issue 4, pp.179-190.

- $\quad$ Huesch, M. (2013). Are there always synergies between productive resources and resource deployment capabilities? Strategic Management Journal, Vol. 34, Issue11, pp. 1288-1313. Crossref

- Kenya Association of Manufacturers, (2018). Manufacturing priority agenda 2018. Nairobi. Kenya Association of Manufacturers.

- $\quad$ Kenya National Bureau of Statistics, (2018). Economic Survey. Nairobi: Government Printer.

- $\quad$ Kiio, J. M., \& Jagongo, A. (2017). Financial risk hedging practices and performance of firms listed in Nairobi Securities Exchange (NSE), Kenya. International Journal of Scientific Research and Innovative Technology, Vol. 4, Issue 1, pp. 11-28.

- $\quad$ Kouvelis, P., Wu, X., \& Xiao, Y. (2019). A framework of hedging decisions for supply chain partners.

Foundations and Trends in Technology, Information and Operations

Management, Vol. 12 Issue (3), pp.189-200. Crossref

- $\quad$ Krey, V., \& Riahi, K. (2013). Risk hedging strategies under energy system and climate policy uncertainties. In Handbook of risk management in energy production and trading (pp. 435-474). Springer, Boston, MA. Crossref

- $\quad$ Lee, H. L. (2014). The Triple-a Supply Chain. Harvard Business Review, Vol. 82, Issue 10, pp. 102-113

- $\quad$ Liu, Z., Chen, L., Li, L., \& Zhai, X. (2014). Risk hedging in a supply chain: Option vs. price discount. International Journal of Production Economics, Vol. 151 Issue 5, pp. 112-120. Crossref

- Merschmann, U., \& Thonemann, U. W. (2011). Supply chain flexibility, uncertainty and firm performance: An empirical analysis of German manufacturing firms. International Journal of Production Economics, Vol. 130, Issue 1, pp. 43-53. Crossref

- $\quad$ PWC, (2010). Industrial Manufacturing: A brief overview of the industrial manufacturing sector in Kenya, Nairobi, Kenya, 2010.

- $\quad$ Schilke, O. (2014). On the contingent value of dynamic capabilities for competitive advantage: the nonlinear moderating effect of environmental dynamism. Strategic Management Journal, Vol. 35, Issue 2, pp. 179-203. Crossref - $\quad$ Spekman, J.W. Kamauff, D.J., \& Salmond, R.E. (2014). At last procurement becomes strategic. Long-Range Plan, Vol. 26, Issue 2, pp. 76-84.

- $\quad$ Stewart, M (2015) Supply chain strategy. Supply chain and logistics institute.

- $\quad$ Supply Chain Opz, (2018). Zara’s Fashion Retail Supply chain strategies, Peerless Media.

- $\quad$ Tang, C. (2006). Perspectives in supply chain risk management. International Journal of

Production Economics, Vol. 103, Issue 2, pp. 451-488. Crossref

- $\quad$ Teece, D. J. (2014). A dynamic capabilities-based entrepreneurial theory of the multinational enterprise. Journal of International Business Studies, Vol. 45, Issue 1, pp. 8-37. Crossref

- Wiesner, R., \& Millet, B. (2012). Strategic approaches in Australian SMEs: deliberate or emergent? Journal of Management and Organization, Vol. 18, Issue 1, pp. 98-122. Crossref 